\title{
Sand minimum transport conditions in gas-solid-liquid three-phase stratified flow in a horizontal pipe at low particle concentrations
}

\author{
Olawale T. Fajemidupe ${ }^{1}$, Aliyu M. Aliyu ${ }^{2 *}$, Yahaya D. Baba ${ }^{3}$, Archibong Archibong-Eso ${ }^{4}$, Hoi Yeung
}

${ }^{1}$ Mewbourne School of Petroleum and Geological Engineering, University of Oklahoma, Norman $100 \mathrm{E}$ Boyd St. Norman, OK-73019

${ }^{2}$ Faculty of Engineering, University of Nottingham, Nottingham NG7 2RD, United Kingdom

${ }^{3}$ Department of Chemical and Petroleum Engineering, Afe Babalola University, PMB 5454, Nigeria

${ }^{4}$ Department of Mechanical Engineering, Cross River University of Technology, Calabar, Nigeria

${ }^{5}$ Oil and Gas Engineering Centre, Cranfield University, Bedfordshire MK43 0AL, United Kingdom

*Corresponding author Email address: Ali.aliyu@ nottingham.ac.uk (AM Aliyu)

Highlights

- Study conducted in sand-water-air flow in a horizontal pipe

- Minimum sand transport conditions were determined by visual observation

- Sand particle concentration and size were varied to see the effect on MTC

- Holdups and pressure gradients were measured for different particle

- Modified Thomas correlation obtained that includes particle concentration.

\begin{abstract}
Sand production in the life of oil and gas reservoirs is inevitable, as it is co-produced with oil and gas from reservoirs. Its deposition in petroleum pipelines poses considerable risk to production and can lead to pipe corrosion and flow assurance challenges. Therefore, it is important that pipe flow conditions are maintained to ensure sand particles are not deposited but in continuous motion with the flow. The combination of minimum gas and liquid velocities that ensure continuous sand motion is known as the minimum transport condition (MTC). This study investigates the effect both of sand particle diameter and concentration on MTC in gas/liquid stratified flow in a horizontal pipeline. We used non-intrusive conductivity sensors for sand detection. These sensors, used for film thickness measurement in gas/liquid flows, was used here for sand detection. We found that MTC increases with increase in particle diameter for the same concentration and also increases as the concentration increases for the same particle diameter. A correlation is proposed
\end{abstract}


for the prediction of sand transport at MTC in air-water flows in horizontal pipes, by including the effect of sand concentration in Thomas's lower model. The correlation accounts for low sand concentrations and gave excellent predictions when compared with the experimental results at MTC.

Keywords: Sand transport; pressure gradient; conductivity probes; stratified flow; minimum transport conditions; multiphase flow

\section{Nomenclature}

\begin{tabular}{|c|c|c|}
\hline \multicolumn{3}{|c|}{$\begin{array}{l}\text { Symbol Description } \\
\text { a. Roman letters }\end{array}$} \\
\hline$C_{v}$ & Particle volume concentration & $v / v$ \\
\hline$D$ & Inside pipe diameter & $m$ \\
\hline$d_{p}$ & Particle diameter & $m$ \\
\hline$f$ & 3-phase friction factor & - \\
\hline$g$ & Acceleration due to gravity & $m / s^{2}$ \\
\hline$H_{g}$ & Gas hold-up & - \\
\hline$H_{l}$ & Liquid hold-up & - \\
\hline$L$ & Pipe length & $m$ \\
\hline$P$ & Pressure & bar \\
\hline$Q_{L}$ & Liquid volumetric flow rate & $m^{3} / s$ \\
\hline$u_{p}, u_{p, c}$ & Particle velocity, subscript $\mathrm{c}$ denotes critical & $m / s$ \\
\hline$u_{c}^{*}$ & Friction velocity & $m / s$ \\
\hline$V_{L}$ & Actual liquid velocity & $\mathrm{m} / \mathrm{s}$ \\
\hline$V_{m i x}$ & Mixture velocity & $m / s$ \\
\hline$V_{s g}$ & Gas superficial velocity & $m / s$ \\
\hline$V_{s g, c}$ & Critical gas superficial velocity & $\mathrm{m} / \mathrm{s}$ \\
\hline$V_{s l}$ & Liquid superficial velocity & $\mathrm{m} / \mathrm{s}$ \\
\hline \multicolumn{3}{|c|}{ b. Greek Letters } \\
\hline$\delta$ & Boundary layer thickness & $\mathrm{m}$ \\
\hline
\end{tabular}




\begin{tabular}{|c|c|c|}
\hline$\varepsilon$ & Pipe wall roughness & - \\
\hline$\rho$ & Fluid density & $\mathrm{kg} / \mathrm{m}^{3}$ \\
\hline$\rho_{G}$ & Gas density & $\mathrm{kg} / \mathrm{m}^{3}$ \\
\hline$\rho_{L}$ & Liquid density & $\mathrm{kg} / \mathrm{m}^{3}$ \\
\hline$\rho_{P}$ & Particle density & $\mathrm{kg} / \mathrm{m}^{3}$ \\
\hline$\mu$ & Fluid viscosity & $P a \cdot s$ \\
\hline$\mu_{\mathrm{g}}$ & Gas viscosity & $P a \cdot s$ \\
\hline$\mu_{L}$ & Liquid viscosity & $P a \cdot s$ \\
\hline$\mu_{m}$ & Viscosity of flow mixture & $P a \cdot s$ \\
\hline$\tau$ & Shear stress & $N / m^{2}$ \\
\hline$\tau_{W L}$ & Liquid-wall shear stress & $N / m^{2}$ \\
\hline eviations & & \\
\hline CR 1 & Conductivity Ring 1 & \\
\hline CR 2 & Conductivity Ring 2 & \\
\hline MTC & Minimum Transport Condition & \\
\hline PSD & Power Spectral Density & \\
\hline$S S 1$ & Sand Sensor 1 & \\
\hline$S S 2$ & Sand Sensor 2 & \\
\hline
\end{tabular}

\section{Introduction}

\subsection{Background}

The prediction of minimum transport conditions (MTC) for sand particles in pipelines carrying oil and gas is essential, and it is an increasingly important topic in the petroleum industry. The majority of today's oil and gas reservoirs are prone to sand production due to the different activities performed on the oil and gas reservoirs to increase the production rate. These activities can include acid stimulation or fracturing to open up the well-bore for higher production rates. Furthermore, chemical and water injection during secondary or tertiary enhanced oil recovery (EOR) and poorly consolidated reservoirs (i.e. reservoirs with low formation strength) all contribute to sand production. According to (Almedeij and Algharaib, 2005), 70\% of the world's oil and gas are produced from reservoirs with low formation strength thereby making sand production currently part and parcel of oil and gas transport. The existence of sand in petroleum pipelines or flowlines 
can cause major setbacks during production, such as pipeline erosion and corrosion especially if the sand particles are not in suspension. These can put increased strain on margins already made tight by recent developments in shale gas production and fluctuating oil prices in the international market.

During production, if the production rate of oil and gas is high, the movement or the impact of sand particles on the wall of the pipe will erode the inner surface of the pipe. On the other hand, if the rate of production of petroleum fluids with sand particles is low, sand deposition will become a problem within the flowline. Deposition of sand particles in flowlines can wreak havoc in several way such as increased pressure loss, localized high velocities, reduction or loss of production when the pipe is partially or completely blocked, and expensive cleaning operations from time to time.

Sand production from the oil and gas reservoirs formation has been a great concern in oil and gas field development and the common approach employed in managing sand production problems is to put in place a down-hole sand exclusion system (such as gravel packs, screen/slotted liners, frac-packs etc.) and also inject chemicals to consolidate the reservoir formation. These can be effective; however, these solutions increase the cost of well completions. Moreover, once the production of sand from the oil and gas reservoir formation surpasses the threshold in the later stages of reservoir life, the virtue or integrity of the production tubing and pipelines will be degraded. Furthermore, it is impossible to produce oil and gas from the reservoirs without producing sand, even when sand exclusion systems are installed down-hole. This is because sand exclusion systems are designed in such a way that fine sands that are co-produced with petroleum fluids are allowed to pass through the opening of the sand exclusion systems.

Due to these various challenges and limitations associated with conventional sand management strategies, there will always be the need to produce oil and gas without greatly affecting production rates and the integrity of the production systems. In order to prevent sand particles being deposited within the pipelines and flow lines during the production of oil and gas, sufficient knowledge of basic design parameters is needed, such as minimum transport conditions (MTCs), sand hold-up, accurate prediction flow regimes and many more (Bello, 2008; Bello et al., 2005). In this study, we introduce a correlation for predicting minimum sand transport conditions, based on the Thomas (1962) model, as a function of liquid and gas properties, sand concentration and particle size. 


\subsection{Literature Review}

Studies related to liquid-gas-solid flows are very scarce, unlike studies related gas-solid and liquid-solid flows, which are quite common. (Scott and Rao, 1971) and (Holte et al., 1987) are among the earliest investigators to develop sand transport models in multiphase flow. (Scott and Rao, 1971) studied particle transport (500 and 100 microns) in single-phase (liquid) and in multiphase (gas-liquid) flow in horizontal pipes. Pressure and saltation velocity of the transported solids were investigated as well their interaction in bubble, plug and slug flow patterns at wide range of slurry concentrations. Their experimental results agreed with Durand's analytical model. (Holte et al., 1987) on the other hand used varied experimental data to modify Wick's model and extended the work done on single-phase water to stratified gas-liquid flows. (Oudeman, 1992) carried out several experiments of sand transport in two phase flows (air-water) and correlation was proposed by defining two dimensionless parameters associated with sand transport rate and fluid flow rate (see Table 1). He performed experiments in a $0.07-\mathrm{m}$ internal diameter test section and used $150 \mu \mathrm{m}(0.15 \mathrm{~mm})$ to $300 \mu \mathrm{m}(0.30 \mathrm{~mm})$ and $690 \mu \mathrm{m}(0.69 \mathrm{~mm})$ particle sizes to determine the clustering effect of smaller particle sizes with gas volume fractions of $0 \%$ to $20 \%$, and liquid velocities between 0.1 and $0.2 \mathrm{~m} / \mathrm{s}$. In order to monitor the effect of viscosity, water was viscosified with carboxymethyl cellulose to $7 \mathrm{cP}$. No concentration of sand was mentioned in the experiment and also the effect of surface tension was determined by adding surfactant. He concluded that the sand transport mode is not influenced directly by the gas-liquid flow regime. In respect to viscosity, he reported that viscosified water having an increased sand carrying capacity, is less able to sweep away or erode the sand bed. Furthermore, In the transition of the stationary bed to moving bed, gas fraction has little influence and gas fraction has considerable influence in the transition of moving bed to suspension.

(Gillies et al., 1997) extended (Meyer-Peter and Muller, 1948)'s, correlation. The correlation models solid transport in single phase liquids but can apply to the transport of solids in multiphase flow systems. Experimental data of three-phase flow (sand-air-liquids) for which a stationary deposit was present in horizontal pipelines with a 2-inch diameter were used to develop this model. They concluded that the injection of gas had little influence on the ability of solids transportation at low liquid superficial velocity when the flow was laminar. However, turbulent flow enhanced solids transport. 
(King et al., 2001) developed minimum transport pressure drop model. The model is an extension of the (Thomas, 1962) model for the prediction of MTCs in two-phase flow (air-water). They derived a relationship relating the friction velocity to the pressure gradient based on the principle of whether the particle diameter is larger or smaller than the thickness of the viscous sublayer. (Thomas, 1962) derived equations for the friction velocity of particle diameters smaller or greater than the laminar or viscous sub-layer thickness. These equations are classified as upper and lower models. (Stevenson and Thorpe, 2002) studied particle transport in smooth stratified flow regimes and developed a correlation to predict the threshold (or critical velocity) of particles in smooth stratified regimes. Their experiments were performed in $0.04 \mathrm{~m}$ and $0.07 \mathrm{~m}$ pipes at an angle of inclination of $1^{\circ}$ and $2^{\circ}$ to the horizontal. The velocity of the particles was investigated by tracking particles at random over a distance of $5.72 \mathrm{~m}$ with a stop watch. This was done by checking particles' transit time between the start point and finish point, which is marked at the end of the pipe. A particle which is spotted by an observer at random is followed from the upstream of the pipe to the downstream of the pipe. The particle sizes studied in these experiments were of sizes 150 to $1180 \mu \mathrm{m}$. The effect of viscosity was also investigated, which ranged from 1 to 4.8 cP. They concluded that average velocity of liquid stratum is linearly proportional to particle velocity and large particles transit quicker than small particles.

(Oroskar and Turian, 1980) model was extended to develop a new predictive model for sand minimum deposition velocity while the (Chisholm, 1967) liquid hold-up model was modified for the calculation of liquid hold-up and the liquid hold-up can then be used to calculate the actual liquid velocity at which sand is deposited.

A sand settling model was proposed by (Salama, 2000). The model can be employed to predict minimum mixture velocity to avoid sand setting in horizontal pipes. This model modifies the exponent of the Oroskar and Turian (1980) model. Danielson (2007) conducted experiments in a $0.069-\mathrm{m}$ pipe diameter with maximum pipe inclinations of $-1.35^{\circ}$ to $+4.0^{\circ}$. The total loop length and test sections were $215 \mathrm{~m}$ and $15 \mathrm{~m}$ respectively. Exxsol D80 and water were used as the liquid phase and air, nitrogen, and $\mathrm{SF}_{6}$ were gas phases. Superficial velocities range of water, oil and gas were $0.01-2 \mathrm{~m} / \mathrm{s}$ and $0.01-8 \mathrm{~m} / \mathrm{s}$ respectively at maximum pressure of $8 \mathrm{bar}$. Sand particle diameter of 280 and $550 \mu \mathrm{m}$ were used as the solid. He developed a correlation for critical solid-liquid velocity based on the data obtained from the experiment. Moreover, he reported that gas rate had no impact on the slip velocity between the carrier liquid and the sand. Ibarra et al. 
(Ibarra et al., 2014) investigated sand transport in stratified flow (air-water) and model was developed for sand minimum deposition velocity. The experimental work was carried out in a 4inch diameter transparent horizontal test loop. Water and air were used as the fluid, while glass beads were used as the solid particle. The gas and liquid velocities range were 5-11 and 0.10$0.14 \mathrm{~m} / \mathrm{s}$ respectively and $211-297 \mu \mathrm{m}$ particles were used in their experiment.

(Najmi et al., 2015) investigated particle transport in low liquid loading with gas flow rate. They studied the effects of: particle shape, particle concentration, particle size and pipe size. In their experiment, however, the effect of viscosity was not studied. (Najmi et al., 2016) conducted experiments by using two pipe diameters of $0.05 \mathrm{~m}$ and $0.1 \mathrm{~m}$. The irregular and regular particles used in the investigation ranged from $20 \mu \mathrm{m}$ to $350 \mu \mathrm{m}$ with volume concentrations of $0.01 \%$ and $0.1 \%$. The liquid used in the experiment is water. A model was used to calculate the liquid holdup in order to determine the actual sand deposition liquid velocity. According to (Najmi et al., 2015), the model of (Fan et al., 2007) was chosen because it was developed mainly for low liquid loading flow conditions. They concluded that critical velocity tends to increase with an increase in particle concentration. Moreover, as the particle size increases, the critical actual liquid deposition or transport velocity increases and the critical velocities for irregular shaped particles (sand) are higher than spherically shaped particles of the same concentration.

Most recently, the effects of particle size and concentration on the critical deposition velocity in both sand-water and air-water-sand flow were also studied by (Leporini et al., 2018). The experiment was carried out in horizontal pipe with internal diameter of $0.063 \mathrm{~m}$ with particle concentration above. It was observed in sand-water experiment with sand concentration above $2.2510^{-4} \mathrm{v} / \mathrm{v}$ that particle size and concentration greatly influenced critical deposition velocity. However, only particle size has great influence on critical deposition velocity when the sand concentration is below $2.2510^{-4} \mathrm{v} / \mathrm{v}$. In sand-gas-water experiment, they pointed out that varying particle size and concentration affect sand deposition characteristics and the presence of gas phase reduces critical deposition velocity. They concluded that slug flow is more efficient in sand transportation when compared to stratified flow. Table 1 gives a summary of the aforementioned experimental studies with their pipe diameters, superficial velocities, fluids used, particle size, and correlations proposed.

Since setting up multiphase particulate flow experiments can be expensive, many investigators have done numerical studies on sand transport. For example, (Murthy et al., 2007) 
investigated the effect of tank diameter, particle size, solid loading and superficial gas velocity using computational fluid dynamics (CFD). They employed a Eulerian multi-fluid model along with the standard $\mathrm{k}-\varepsilon$ turbulence model to simulate the gas-liquid, solid-liquid and gas-liquidsolid flows in a stirred tank. Good agreement was reported between predicted and the experimental results for all parameters tested in this study.

(Liu et al., 2015) numerically studied the dynamic behaviour of multiphase flow in a gassolid-liquid mixture system based on particle methods. Solid particle collision and contact effects were studied using distinct element methods. Viscosity and empirical drag force models were employed for the hydrodynamic interactions between solid particles and fluid for the simulation. They observed that the interactions that exist between the particle of the same solid and fluid in which they are found contribute greatly to bubble behaviour in the solid particle-liquid mixture. Furthermore, (Sun and Sakai, 2015) modelled gas-solid-liquid flows using CFD to show the validity of a DEM-VOF approach. The particle phase was tracked by a discrete element method (DEM) as detached entities. There was good agreement between their simulation and secondary experimental results reported in their investigation.

The literature review shows that there are comprehensive studies on the effect of gas and liquid velocities as well as particle size and concentration but these limited to high sand concentrations. On the other hand, there seem to be a general lack of consistency in the form of derived correlations for sand particle transport (see Table 1). This notwithstanding, many authors have adopted the Thomas (1962) model and fitting their experimental data to include a sand concentration correction term, but again as we will show later in this study, these fail to adequately model sand behaviour at concentrations lower than $0.001 \% \mathrm{v} / \mathrm{v}$. Hence, we attempt to improve this and present valuable experimental data for sand-gas-liquid transport.

\section{Experimental}

\subsection{Description of rig}

The experiments were carried out on the 2-inch horizontal test facility in the Oil and Gas Engineering Centre Laboratory at Cranfield University. The whole experimental set-up is illustrated in Figure 1 (a). It consists of a horizontal pipe with an inner diameter of $0.0504 \mathrm{~m}$. The 2 -inch test rig constitutes a loop length of $25 \mathrm{~m} ; 10.5 \mathrm{~m}$ of that is PVC pipe that serves as the water supply inlet and the remainder is of a Perspex pipe material. Two flush-mounted conductivity-based sand monitoring 
sensors (uncertainty of $\pm 3.3 \%$ and identical to those employed by (Aliyu et al., 2017b, 2016; Aliyu et al., 2016; Aliyu et al., 2017; Almabrok et al., 2016) in measuring liquid film thickness), given in Figure 1 (b) and (c) were installed about $6 \mathrm{~m}$ after the air and sand injection point along the horizontal pipe but $0.21 \mathrm{~m}$ apart from each other. The second sand sensor was placed within the conductivity ring sensors. (Fajemidupe, 2016) showed the effectiveness of such sensors in the detection of sand flow in pipes, and Figure 1 (d) shows a sample sand calibration curve which was done in static conditions using solutions with known incremental sand concentrations. The raw voltage from the sand sensors are normalised as follows:

$$
\text { Normalised voltage }=\frac{\text { Voltage of sand with water }- \text { Voltage of empty pipe }}{\text { Voltage of water only (no sand)- Voltage of empty pipe }}
$$

For a pipe with a certain water superficial velocity without sand particles, the normalised voltage is unity. For flows with sand, there is signal attenuation of the voltage transmitted and the receiver electrodes output voltages less than the transmitted depending on the sand concentration. In such situations, the normalised voltages are between zero and unity. In all experiment runs, the voltage response from each probe was recorded for 120 seconds after steady state is achieved.

Transducers were also installed on the test rig to give measurements of point pressures from which pressure gradients were determined. The first pressure transducer was positioned at about $1.5 \mathrm{~m}$ from the first sand sensor and about $4 \mathrm{~m}$ from the sand and air injection points. Furthermore, the test section was equipped with 2-inch internal diameter conductivity ring sensors to measure the liquid hold-up. The calibration procedures of the film thickness and conductivity ring probes have previously been reported in detail (Aliyu et al., 2017a; Yan, 2010). Table 2 summarises the installed instrumentation, and their uncertainties while Table 3 shows the test matrix and sand particle properties.

\subsection{Experimental Procedure}

Stratified flow is firstly established in the test section at the desired flow conditions. Then, sandwater mixture of required concentration is prepared in the sand mixing tank. Prior to the injection of sand-water mixture into the test line, the sand-liquid composition was mixed thoroughly and injected into the horizontal test section via a 0.25 -inch flexible pipe that connects the sand injection pump to the test section. The gas flow rate at specific intervals for every fixed value of water superficial velocity is gradually decreased to achieve the minimum transport conditions (MTCs) and different sand-water flow regime in the test section. The experimental test matrix is as shown in Table 3 and depicts the sand properties used. 
The two conductivity sensors used here were installed downstream of the sand injection point and data obtained were studied and critically examined to determine the different sand-water flow patterns. Furthermore, visual observation and several video clips were taken to analyse the sandwater flow regime in support of the sand sensor analysis. The signals obtained as time series from the conductivity sand sensors were analysed in such a way that the normalized voltage values from the sensor were plotted with the time.

\section{Results and discussion}

\subsection{Sand flow regimes}

The sand settling experiment in air-water flow was carried out by reducing the gas superficial velocity from $5.0 \mathrm{~m} / \mathrm{s}$ to $4.4 \mathrm{~m} / \mathrm{s}$. At $4.4 \mathrm{~m} / \mathrm{s}$ gas superficial velocity, all sand particles were still suspended in the liquid phase and none was seen moving at the bottom of the pipe. During the sand settling test MTCs and different sand-air-water flow regimes were encountered. We again mention that the minimum transport condition (velocity) for sand particles under stratified flow regime is defined as the combined minimum gas and liquid velocities at which all sand particles have sufficient energy to keep them moving in the liquid phase along the pipe. The sand-water settling tests were conducted to determine the different sand-water flow regimes and MTC. The liquid superficial velocity started from the highest to determine full suspension and gradually reduced to determine other sand-water flow regimes, such as streak, saltation and moving dunes. The reduction in the liquid superficial velocities caused all other sand-water flow regimes to occur. Figure 2 depicts sand-water flow regimes with MTC for 212, 500 and $800 \mu \mathrm{m}$ respectively at concentration of 200 $\mathrm{lb}$ and $500 \mathrm{lb} / 1000 \mathrm{bbl}$. Figure 2 (a) shows the sand flow regime for particle size of $212 \mu \mathrm{m}$ while Figures 2 (b) and (c) show the regime for larger particles of 500 and $800 \mu m$ respectively. As can be seen, for both particle concentrations, MTC is progressively postponed for the larger particle sizes and concentrations. This is consistent since larger and more highly concentrated particles will have more settling inertia and be harder to transport than smaller and more sparsely concentrated particles.

\section{Sand Dunes}

Figure 3 (a) depicts the sand moving dunes (in sand-air-water) flow regime of sand particles with a size of $212 \mu \mathrm{m}$ at a concentration of $500 \mathrm{lb} / 1000 \mathrm{bbl}$ with a liquid superficial velocity of $0.10 \mathrm{~m} / \mathrm{s}$. The sand moving dunes appear as the gas superficial velocity was reduced from $4.2 \mathrm{~m} / \mathrm{s}$ to $4.0 \mathrm{~m} / \mathrm{s}$ and dunes formed are slower in movement and increase in size by between 20 and 30\%. The 
reduction of gas superficial velocity resulted into sand particles becoming denser at the bottom of the pipe when compared with the sand-air-water flow regime at a gas superficial velocity of $4.0 \mathrm{~m} / \mathrm{s}$.

\section{Sand Streak below MTC}

A dense streak of sand appeared at the bottom of the pipe as the gas superficial velocity is below gas superficial velocity at MTC. This occurred when the gas superficial velocity was reduced to 4.2 $\mathrm{m} / \mathrm{s}$. Figure 3 (b) depicts sand-air-water flow below the MTC $\left(V_{s l}=0.28 \mathrm{~m} / \mathrm{s}, V_{s g}=4.2 \mathrm{~m} / \mathrm{s}\right)$. Denser sliding sand streaks are observed at the bottom of the pipe. Sensor signals are farther from unity when compared with signals from the suspension regime.

\section{Sand Streak at MTC}

Sand streaks are ribbons of sand formed and can be seen to be streamlined along the direction of flow. The reduction of gas superficial velocity from $4.4 \mathrm{~m} / \mathrm{s}$ to $4.3 \mathrm{~m} / \mathrm{s}$ at the same liquid superficial velocity of $0.31 \mathrm{~m} / \mathrm{s}$ caused sand particles to start moving hence resulting in the attainment of the MTC. A snapshot of this condition is shown in Figure 3 (c). At this air-water flow condition, a few sand particles were transported as streaks at the bottom of the pipe within the liquid phase. This is at sand particle size of $212 \mu \mathrm{m}$ at a concentration of $500 \mathrm{lb} / 1000 \mathrm{bbl}$ at MTC.

\section{Sand Transport above MTC}

The snapshot when sand transport is above MTC $\left(V_{s l}=0.34 \mathrm{~m} / \mathrm{s}, V_{s g}=4.4 \mathrm{~m} / \mathrm{s}\right)$ for sand particles with a diameter of $212 \mu \mathrm{m}$ at a concentration of $500 \mathrm{lb} / 1000 \mathrm{bbl}$ is shown in Figure 3 (d). At these velocities all the sand particles were suspended in the liquid phase and none was seen transported at the bottom of the pipe or across the gas-liquid interface. This is a fully suspended sand regime.

\subsection{Signal cross correlation}

The average velocity measurement along the flow direction can be determined by the cross correlation of two sensor signals. Cross correlation is the standard method that measures the degree to which two signals relate to each other with respect to the displacement of time that exists between them. Identical signals tend towards unity when cross correlated. However, cross correlation for dissimilar signals will be closer to zero. Considering two different signals, $S S 1(t)$ and $S S 2(t)$, then the cross-correlation function $R_{S S 1-S S 2}(\tau)$ is given by:

$$
R_{S S 1-S S 2}(\tau)=\lim _{N \rightarrow \infty} \frac{1}{N} \int_{0}^{N} S S 1(t) S S 2(t+\tau) d t
$$


where $\tau$ is the time delay between the two signals and it can be determined by searching for the time position of the maximum cross correlation coefficient. The average sand particle flow velocity $V_{p}$ can be calculated by dividing the separation between the sensors $L$ and the determined time delay:

$$
u_{p}=\frac{L}{\tau}
$$

where $L$ is the distance between the centres of the two sensors. At MTC, this particle velocity is called the critical sand transport velocity $u_{p, c}$.

\subsection{Particle Size Effect on MTC in Stratified Flow}

The effect of particle sizes on MTC was investigated. Three sand particle sizes $(212,500$ and 800 $\mu \mathrm{m})$ at the same volume concentration were examined to determine the effect of particle size on MTC. Observation from Figure 4 shows that the MTC for $500 \mu m$ is higher than the MTC for 212 $\mu \mathrm{m}$ for the same volume concentration $(200 \mathrm{lb} / 1000 \mathrm{bbl})$. Therefore, as the particle diameter increases, the MTC also increases for the same volume concentration. This situation is illustrated in Figure 4 (a) with $8 \%$ error bars representing the percentage standard deviation of a triplicate of observations. The particles are transported in stratified wavy flow. These results correspond with what was reported by earlier investigators in sand-air-water systems (Dabirian et al., 2015; Najmi et al., 2015).

\subsection{Effect of Sand Concentration on MTC in Stratified Flow}

The effect of concentration on MTC for particle diameter in stratified flow was investigated in this study. Two volume concentrations were investigated (200 Ib and 500Ib/1000) with three different particles sizes $(212,500$ and $800 \mu \mathrm{m})$. Figure 4 (b) gives the trend of MTC with concentration, gas and liquid superficial velocities for $212 \mu \mathrm{m}$ sand particles. It can be deduced that as the concentration increases from 200 to $500 \mathrm{lb} / 1000 \mathrm{bbl}$, the superficial liquid velocities at MTC increases. This behaviour was also observed for all particle sizes. Therefore, the MTCs for $500 \mathrm{lb} / 1000 \mathrm{bbl}$ were higher than those of $200 \mathrm{lb} / 1000 \mathrm{bbl}$ and is consistent with the fact that more densely concentrated particles will be harder to transport than lesser concentrated ones.

These observations are similar to those reported by (Najmi et al., 2015) and (Dabirian et al., 2015). The former used both spherical and irregularly-shaped particles of size ranging between 20 and $300 \mu \mathrm{m}$ in a 100-mm pipe, but very low particle concentrations were of 0.0001 and $0.001 \mathrm{v} / \mathrm{v}$ were used; while the latter study used irregularly shaped particles in a 100-mm pipe and with sand concentrations much lower than that of Najmi and cowokers. In both studies as well as the current, 
particles were transported in stratified wavy flow. At MTC as shown in Table 4, all the holdups are between 0.20 and 0.27 regardless of particle size or concentration and are identified to be in the stratified flow regime. To obtain the actual liquid velocity at MTC, the superficial velocity is divided by the liquid holdup (i.e. $\left.V_{L, M T C}=V_{s l}(a t M T C) / H_{l}\right)$. Therefore, this is the actual velocity required to move static sand dunes into moving streaks as if only water occupies the entire pipe.

\subsection{Calculation of the 3-phase friction factor at MTC}

The 3-phase friction factor $f$ in sand-air-water flow is important in calculating the friction velocity $u_{c}^{*}$. Practically, it is determined from the measured pressure gradient for each experimental condition and calculated as follows:

$$
f=-\frac{d P}{d L} \frac{D}{\rho_{\text {mix }} V_{\text {mix }}^{2}}
$$

where $V_{\text {mix }}$ is the mixture velocity and is calculated as the sum total of the actual gas, liquid, and sand velocities at MTC; $\rho_{\text {mix }}$ is the mixture density given by $\rho_{\text {mix }}=H_{l} \rho_{l}+\left(1-H_{l}\right) \rho_{g}+C_{v} \rho_{p}$; $H_{l}$ is the liquid holdup measured by the conductivity rings, and subscript $p$ refers to the sand particles. Figure 5 depicts the friction factor calculated using Equation 4, which takes account of sand concentration, plotted on the Moody diagram in order to compare with single-phase water values at different pipe roughness. As can be seen, all the points tested fall in the turbulent flow region, and range from low to high roughness depending mostly on the mixture Reynolds number. The sand mixture friction factors were consistently above those for smooth pipes which is consistent with observations by other authors (e.g. (Aliyu et al., 2017c, 2016; Belt et al., 2009)) who reported in increase in friction factor with increased interfacial friction. This is also related to increased pressure drop within the pipe, as given by the relationship in Equation 4. As a result of this comparison, we were confident that the assumptions and procedure followed to calculate the friction factors of the sand-water mixture in the pipe and resulting values are reasonable and can be used for further analysis such as data correlation.

\subsection{Correlation of sand MTC data}

One of the objectives of this study is to advance the Thomas lower model to enhance its robustness. A main drawback of the Thomas lower model is that a concentration correction term has not been considered. Concentration is one of the important factors that affect sand transport at MTC in fluid flow. Furthermore, Thomas also proposed that the wall friction velocity is constant from a concentration of 0.01 to $0.06 \% \mathrm{v} / \mathrm{v}$ for sand particles smaller than the laminar sublayer. Therefore, 
shear velocity at infinite dilution was assumed to be $C_{v}=0.001 \% \mathrm{v} / \mathrm{v}$. King et al. (2001) recommended Thomas's lower model (1962) for the calculation of friction velocity $\mathrm{u}_{0}{ }_{0}$ at MTC. The associated frictional pressure gradient can then also be calculated. However, the Thomas lower model (1962) does not have a concentration correction term. In an earlier paper (Thomas, 1961), claimed that for particles tinier than the laminar sublayer, the wall shear velocity remained constant at $\mathrm{C}_{\mathrm{v}}$ from 0.01 to $0.06 \% \mathrm{v} / \mathrm{v}$. Therefore, he used the friction velocity at $\mathrm{C}_{\mathrm{v}}=0.001 \% \mathrm{v} / \mathrm{v}$ as the friction velocity at infinite dilution $\left(\mathrm{C}_{\mathrm{v}} \approx 0 \%\right.$, i.e. very few particles). However, as a result of the absence of shear velocity data for concentrations lower than $0.001 \% \mathrm{v} / \mathrm{v}$, this theory is unproven. King et al. (2001) then stated that the thickness of the laminar sublayer $\delta$ could be estimated by $\delta=$ $62 D R e_{l}^{-7 / 8}$ which, as Kosky (1971) showed, can be arrived at by integrating Prandtl's $1 / 7^{\text {th }}$ power law velocity profile in the flowing liquid. In the present work, sand with maximum size of 800 microns mean particle diameter was used, which will not exceed the thickness until $V_{s l}=1.35 \mathrm{~m} / \mathrm{s}$ for water flow. In this study, the maximum $\mathrm{V}_{\mathrm{sl}}$ values are $0.09 \mathrm{~m} / \mathrm{s}$. Therefore, our sand particles were found smaller than the thickness of the laminar sublayer, and only Thomas lower-type models apply.

Comparison of Thomas's lower model results with experimental MTCs from this study showed that there were discrepancies between them. The inaccuracies in the Thomas lower model may be attributed to the absence of a solid (sand) concentration factor. To advance the Thomas lower model at low sand concentrations, we obtained data at MTCs in air-water through experiments in the 2inch horizontal pipe, described earlier. A concentration range of $5.39 \times 10^{-5} \mathrm{v} / \mathrm{v}(50 \mathrm{lb} / 1000 \mathrm{bbl})$ to $5.39 \times 10^{-4} \mathrm{v} / \mathrm{v}(500 \mathrm{lb} / 1000 \mathrm{bbl})$ was considered. The sand transport velocities in air-water at MTCs were first converted to actual liquid velocities and the friction factors were obtained from pressure gradient measurements.

A correlation in the form of $u_{c}^{*}-u_{0}^{*}=K C_{v}^{\alpha}$ will be used to advance the Thomas lower model. This type of correlation has been recommended by (Zandi and Haydon, 1971) as well as Thomas himself in the same 1962 paper. In order to have one correlation that fits all experimental data points at MTC in our air-water experiments, data from flow conditions $\left(V_{s l}=0.06,0.07,0.08\right.$ and $\left.0.09 \mathrm{~m} / \mathrm{s}\right)$ obtained from 2-inch test facilities is put together. The following procedure was followed:

1. Collect data for all liquid superficial velocities and for the range of sand concentrations $\left(5.39 \times 10^{-5} \leq C_{v} \leq 4.9 \times 10^{-4}\right)$. Convert the test point of the particle critical transport velocity, 
obtained by cross-corelating the two sensor signals SS1 and SS2 (described in section 3.2), to a friction velocity using:

$$
u_{c}^{*}=\left(\sqrt{\frac{f}{2}}\right) * u_{p, c}
$$

where $f$ is the 3-phase friction factor calculated using Equation 4.

2. Test $50 \mathrm{lb} / 1000 \mathrm{bbl}$ is used for infinite dilution from the 2-inch facility:

$$
u_{o}^{*}=u_{c\left(\frac{50 l b}{1000 b b l}\right)}^{*}
$$

3. Fit all data to $u_{c}^{*}=u_{0}^{*}+K C_{v}^{\alpha}$ to determine the value of the slope $\mathrm{K}$ and the index $\alpha$. The left-hand side and the intercept alone are the Thomas lower model. We assume a power law relationship as a correction to the Thomas lower model in order to incorporate the effect of particle concentration $C_{v}$.

4. Convert $\mathrm{u}_{\mathrm{c}}^{*}$ to actual liquid velocity at MTC.

After the above procedure was followed, the correlation for sand MTC in air-water stratified flow is given as:

$$
u_{c}^{*}=u_{0}^{*}+0.7231 C_{v}^{0.3977}
$$

where $u_{0}^{*}$ is given by the Thomas (1962) lower model:

$$
u_{0}^{*}=\left[100 u_{t}\left(\frac{v}{d_{p}}\right)^{2.71}\right]^{0.269}
$$

where $d_{p}$ is particle diameter, $u_{0}^{*}$ is friction velocity, $v$ is kinematic viscosity and $u_{t}$ is particle settling velocity. Figure 6 shows a plot of Equation 7 together with the current experimental data and that of (Ibarra et al., 2014). Ibarra and co-workers' used sand concentrations between 0.001 and $0.0048 \% \mathrm{v} / \mathrm{v}$. However, their study did not consider concentrations below $0.001 \% \mathrm{v} / \mathrm{v}$ which all of our data come from. As can be seen, Equation 7, is a good fit to both datasets and can be said to effectively reflect the effect of low to medium particle concentrations.

The correlation's results were compared with the experimental results from the sand transport at MTC as shown in Table 5 for liquid superficial velocities of 0.06, 0.07, 0.08 and 0.09 $\mathrm{m} / \mathrm{s}$ at different concentration and sand particle diameters. It was found that the proposed correlation gave good predictions when compared with the experimental results at MTC at many of the test conditions. The percentage absolute error (PAE) was used to quantify the correlation's performance. It is defined as follows: 


$$
P A E=\frac{\left|V_{L, M T C, \text { exp }}-V_{L, M T C, \text { pred }}\right|}{V_{L, M T C, \text { pred }}} \times 100 \%
$$

where the subscripts exp and pred refer to experimental and predicted respectively. As can be seen from Table 4 , the deviations range from 0.00 to $24.32 \%$ with a median deviation of $7.14 \%$. All the highest deviated points occurred at the smallest and largest particle diameters i.e. 212 and $800 \mu \mathrm{m}$ suggesting that the correlation works best at intermediate particle sizes which in this case is represented by the $500 \mu \mathrm{m}$-sized particles. Nevertheless, Equation 7 represents an improvement on previous correlations such as those of (Yan, 2010) which was a modification of Thomas's lower model that includes the effect of particle concentration.

On the other hand, it does appear that the postulation that the constant shear velocity postulation by Thomas at particle concentrations lower than $0.001 \% \mathrm{v} / \mathrm{v}$ do not seem to hold since in the plot, there is a clear steep rise in $\left(u_{c}^{*}-u_{0}^{*}\right)$ from 0 to $0.04 \mathrm{~m} / \mathrm{s}$. while Yan's work was only for sand transport in single-phase liquid, here, the effect of the shearing gas is included. This gas effect manifests in Equation 4 by way of the 3-phase mixture velocity and friction factor.

Lastly, it is important to stress that our correlation holds only for the range of conditions it was developed from i.e. those shown in Figure 6 and must be used with great caution outside these ranges e.g. within simulation codes. While the correlation can easily be extrapolated to higher sand concentration, the accuracy cannot be guaranteed since it is not backed by any measurements. As a suggestion for future work, the effect of intermediate and higher sand concentrations than considered here need to be examined. We also suggest that the effect of liquid viscosity needs to be explored since viscosity is known to greatly affect shear, mass, and momentum transport within the boundary layer.

\section{Conclusions}

Sand is usually transported in oil and gas pipelines where it is undesirable if it settles within the pipe. This brings rise to erosion/corrosion as well as flow assurance issues. It is therefore important that flow conditions should ensure continuous sand transport such that just the right amount of energy is expended. Such flow conditions are referred to as the minimum transport conditions. In this article, we measured the minimum transport conditions in horizontal sand-gas-liquid flows for three different sand particle sizes and two sand concentrations in the stratified flow regime. Visual observations were used to classify the sand flow regimes as suspension, sand streak, and moving sand dunes. Together with liquid holdup measured with the ring conductivity rings, and the sand 
concentration, the pressure gradient was used to calculate the friction factor. This was then used to estimate the friction velocity and then related to the minimum transport liquid velocity in a correlation according to Thomas (1962) lower model. However, as an improvement on the Thomas model, we include the effect of sand concentration via a power law relationship. Improved predictions were obtained from this correlation and we suggest that more work should to be done to further expand the current range of sand concentrations covered.

\section{Competing interests}

None.

\section{Acknowledgement}

The first and fourth authors OTF and AAE express their deep appreciation for the funding they received from Cranfield University's Oil and Gas Engineering Centre for their PhD studies. Authors AMA and YDB would like to express sincere gratitude to the Nigerian Government for funding their PhDs through the Petroleum Technology Development Fund's Overseas Scholarship Scheme (PTDF/E/OSS/PHD/AMA/622/12 and PTDF/E/OSS/PHD/BYD/532/12 respectively). Sincere appreciation is extended to Mr. Stan Collins and his staff for their tireless effort in the laboratory to ensure the rigs and other equipment run smoothly. 


\section{References}

Aliyu, A.M., Almabrok, A.A., Baba, Y.D., Archibong, A.-E., Lao, L., Yeung, H., Kim, K.C., 2017a. Prediction of entrained droplet fraction in co-current annular gas-liquid flow in vertical pipes. Exp. Therm. Fluid Sci. 85. https://doi.org/10.1016/j.expthermflusci.2017.03.012

Aliyu, A.M., Almabrok, A.A., Baba, Y.D., Lao, L., Yeung, H., Kim, K.C., 2017b. Upward gas-liquid two-phase flow after a U-bend in a large-diameter serpentine pipe. Int. J. Heat Mass Transf. 108. https://doi.org/10.1016/j.ijheatmasstransfer.2016.12.069

Aliyu, A.M., Baba, Y.D., Lao, L., Yeung, H., Kim, K.C., 2017. Interfacial friction in upward annular gas-liquid two-phase flow in pipes. Exp. Therm. Fluid Sci. 84, 90-109. https://doi.org/10.1016/j.expthermflusci.2017.02.006

Aliyu, A.M., Baba, Y.D., Lao, L., Yeung, H., Kim, K.C., 2017c. Interfacial friction in upward annular gas-liquid two-phase flow in pipes. Exp. Therm. Fluid Sci. 84. https://doi.org/10.1016/j.expthermflusci.2017.02.006

Aliyu, A.M., Lao, L., Almabrok, A.A., Yeung, H., 2016. Interfacial shear in adiabatic downward gas/liquid cocurrent annular flow in pipes. Exp. Therm. Fluid Sci. 72. https://doi.org/10.1016/j.expthermflusci.2015.10.025

Aliyu, A.M., Lao, L., Almabrok, A.A., Yeung, H., 2016. Interfacial shear in adiabatic downward gas/liquid cocurrent annular flow in pipes. Exp. Therm. Fluid Sci. 72, 75-87. https://doi.org/10.1016/j.expthermflusci.2015.10.025

Almabrok, A.A., Aliyu, A.M., Lao, L., Yeung, H., 2016. Gas/liquid flow behaviours in a downward section of large diameter vertical serpentine pipes. Int. J. Multiph. Flow 78, 25-43. https://doi.org/http://dx.doi.org/10.1016/j.ijmultiphaseflow.2015.09.012

Almedeij, J.H., Algharaib, M.K., 2005. Influence of sand production on pressure drawdown in horizontal wells: Theoretical evidence. J. Pet. Sci. Eng. 47, 137-145. https://doi.org/10.1016/j.petrol.2005.03.005

Bello, O.O., 2008. Modeling particle transport in gas-oil-sand multiphase flows and its applications to production operations. Clausthal University.

Bello, O.O., Reincke, K.M., Teodoriu, C., 2005. Measurement of sand velocity and holdup distributions in multiphase slug using digital image analysis techniques, in: 12th International Conference on Multiphase Production Technology. BHR Group, Barcelona, pp. 171-185.

Belt, R.J., Van't Westende, J.M.C., Portela, L.M., 2009. Prediction of the interfacial shear-stress in vertical annular flow. Int. J. Multiph. Flow 35, 689-697. https://doi.org/10.1016/j.ijmultiphaseflow.2008.12.003

Chisholm, D., 1967. Lockhart-Martinelli Basis for the Correlation Flow for Two-Phase. Int. Commun. Heat Mass Transf. 10, 1767-1778.

Dabirian, R., Mohan, R.S., Shoham, O., Kouba, G., 2015. Sand Transport in Stratified Flow in a Horizontal Pipeline. SPE Annu. Tech. Conf. Exhib. 28-30. https://doi.org/10.2118/174960-MS

Danielson, T.J., Co, C., 2007. Sand Transport Modeling in Multiphase Pipelines. Offshore Technol. Conf. 
https://doi.org/10.4043/18691-MS

Davies, J.T., 1987. Calculation of critical velocities to maintain solids in suspension in horizontal pipes. Chem. Eng. Sci. 42, 1667-1670. https://doi.org/10.1016/0009-2509(87)80171-9

Fajemidupe, O.T., 2016. Effect of particle size on sand deposition in single-phase and multiphase pipelines. Cranfield University.

Fan, Y., Wang, Q., Zhang, H.-Q., Danielson, T.J., Sarica, C., 2007. A Model To Predict Liquid Holdup and Pressure Gradient of Near-Horizontal Wet-Gas Pipelines. https://doi.org/10.2118/95674-PA

Gillies, R.G., McKibben, M.J., Shook, C.A., 1997. Pipeline flow of gas, liquid and sand mixtures at low velocities. J. Can. Pet. Technol. 36, 36-42. https://doi.org/10.2118/97-09-03

Holte, S., Anglesen, S., Kvernvold, O., Raesder, J.H., 1987. Sand bed formation in horizontal and near horizontal gas-liquid-sand flow, in: The European Two-Phase Flow Group Meeting. Trondheim, p. 205.

Ibarra, R., Mohan, R.S., Shoham, O., 2014. Critical Sand Deposition Velocity in Horizontal Stratified Flow. SPE Int. Symp. Exhib. Form. Damage Control 26-28. https://doi.org/10.2118/168209-MS

King, M.J.S., Fairhurst, C.P., Hill, T.J., 2001. Solids Transport in Multiphase Flows-Application to HighViscosity Systems. J. Energy Resour. Technol. 123, 200. https://doi.org/10.1115/1.1385382

Kosky, P.G., 1971. Thin liquid films under simultaneous shear and gravity forces. Int. J. Heat Mass Transf. 14, 1220-1224. https://doi.org/10.1016/0017-9310(71)90216-X

Leporini, M., Marchetti, B., Corvaro, F., di Giovine, G., Polonara, F., Terenzi, A., 2018. Sand transport in multiphase flow mixtures in a horizontal pipeline: An experimental investigation. Petroleum. https://doi.org/10.1016/j.petlm.2018.04.004

Liu, X., Aramaki, Y., Guo, L., Morita, K., 2015. Numerical simulation of gas-liquid-solid three-phase flow using particle methods. J. Nucl. Sci. Technol. 52, 1480-1489. https://doi.org/10.1080/00223131.2015.1012132

Meyer-Peter, E., Muller, R., 1948. Formulas for Bed-load Transport, in: Proceedings of the 2nd Meeting of the International Association for Hydraulic Structures Research. pp. 39-64.

Murthy, B.N., Ghadge, R.S., Joshi, J.B., 2007. CFD simulations of gas-liquid-solid stirred reactor: Prediction of critical impeller speed for solid suspension. Chem. Eng. Sci. 62, 7184-7195. https://doi.org/10.1016/j.ces.2007.07.005

Najmi, K., Hill, A.L., McLaury, B.S., Shirazi, S.A., Cremaschi, S., 2015. Experimental Study of Low Concentration Sand Transport in Multiphase Air-Water Horizontal Pipelines. J. Energy Resour. Technol. 137, 032908. https://doi.org/10.1115/1.4029602

Najmi, K., Mclaury, B.S., Shirazi, S.A., Cremaschi, S., 2016. Low concentration sand transport in multiphase viscous horizontal pipes: An experimental study and modeling guideline. AIChE J. 62, 1821-1833. https://doi.org/10.1002/aic.15131

Oroskar, A.R., Turian, R.M., 1980. Critical Velocity in Pipeline Flow of Slurries. AIChE J. 26, 550-558. https://doi.org/10.1002/aic.690260405

Oudeman, P., 1992. Sand Transport and Deposition in Horizontal Multiphase Trunklines of Subsea Satellite 
Developments. Offshore Technol. Conf. 8, 0-4. https://doi.org/10.4043/7059-MS

Salama, M.M., 2000. Sand Production Management. J. Energy Resour. Technol. 122, 29. https://doi.org/10.1115/1.483158

Scott, D.S., Rao, P.K., 1971. Transport of solids by gas-liquid mixtures in horizontal pipes. Can. J. Chem. Eng. 49, 302-309. https://doi.org/10.1002/cjce.5450490302

Stevenson, P., Thorpe, R.B., 2002. Velocity of isolated particles along a pipe in stratified gas-liquid flow. AIChE J. 48, 963-969. https://doi.org/10.1002/aic.690480506

Sun, X., Sakai, M., 2015. Three-dimensional simulation of gas-solid-liquid flows using the DEM-VOF method. Chem. Eng. Sci. 134, 531-548. https://doi.org/10.1016/j.ces.2015.05.059

Thomas, D.G., 1962. Transport characteristics of suspensions: Part IV. Friction loss of concentrated???flocculated suspensions in turbulent flow. AIChE J. 8, 266-271. https://doi.org/10.1002/aic.690080227

Thomas, D.G., 1961. Transport characteristics of suspensions: II. Minimum transport velocity for flocculated suspensions in horizontal pipes. AIChE J. 7, 423-430. https://doi.org/10.1002/aic.690070316

Yan, W., 2010. Sand transport in multiphase pipelines. Cranfield University.

Zandi, I., Haydon, J.A., 1971. A Pneumo-slurry System of Collecting and Removing Solid Wastes, in: Zandi, I. (Ed.), Advances in Solid-Liquid Flow in Pipes and Its Application. Pergamon Press, p. 306. 


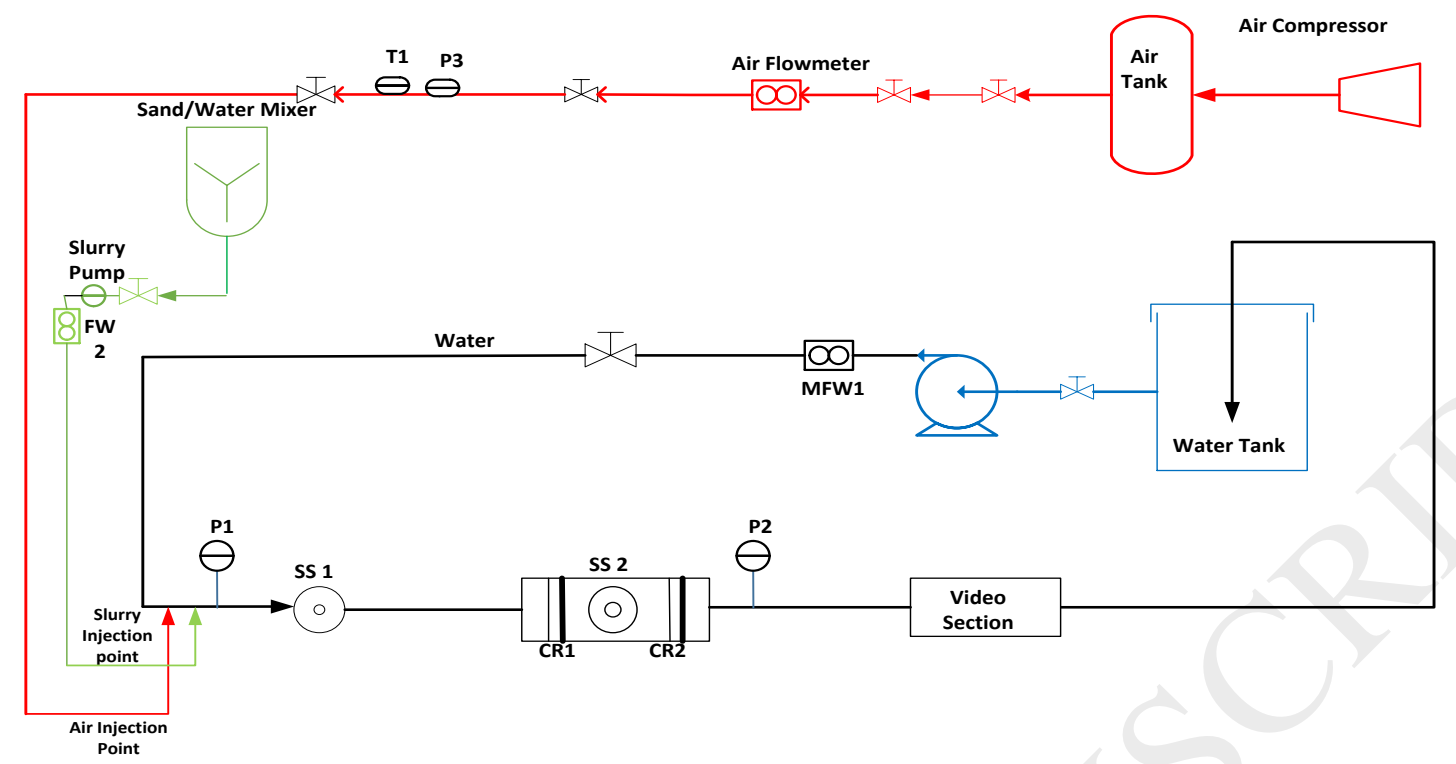

(a)
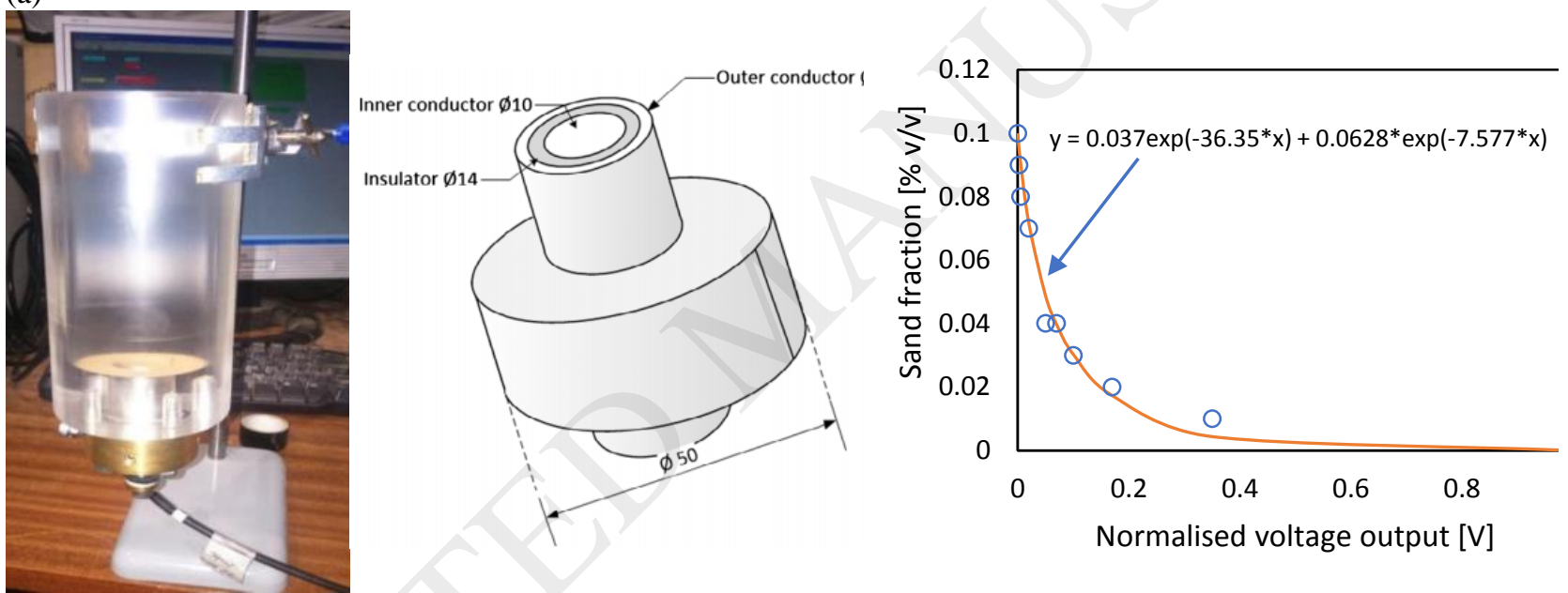

(b)

(c)

(d)

Figure 1: (a) Two-inch sand transport test facility (b) flush-mounted conductivity sand probe in calibration assembly (c) details of probe (dimensions in $\mathbf{~ m m}$ ) (d) probe calibration curve 

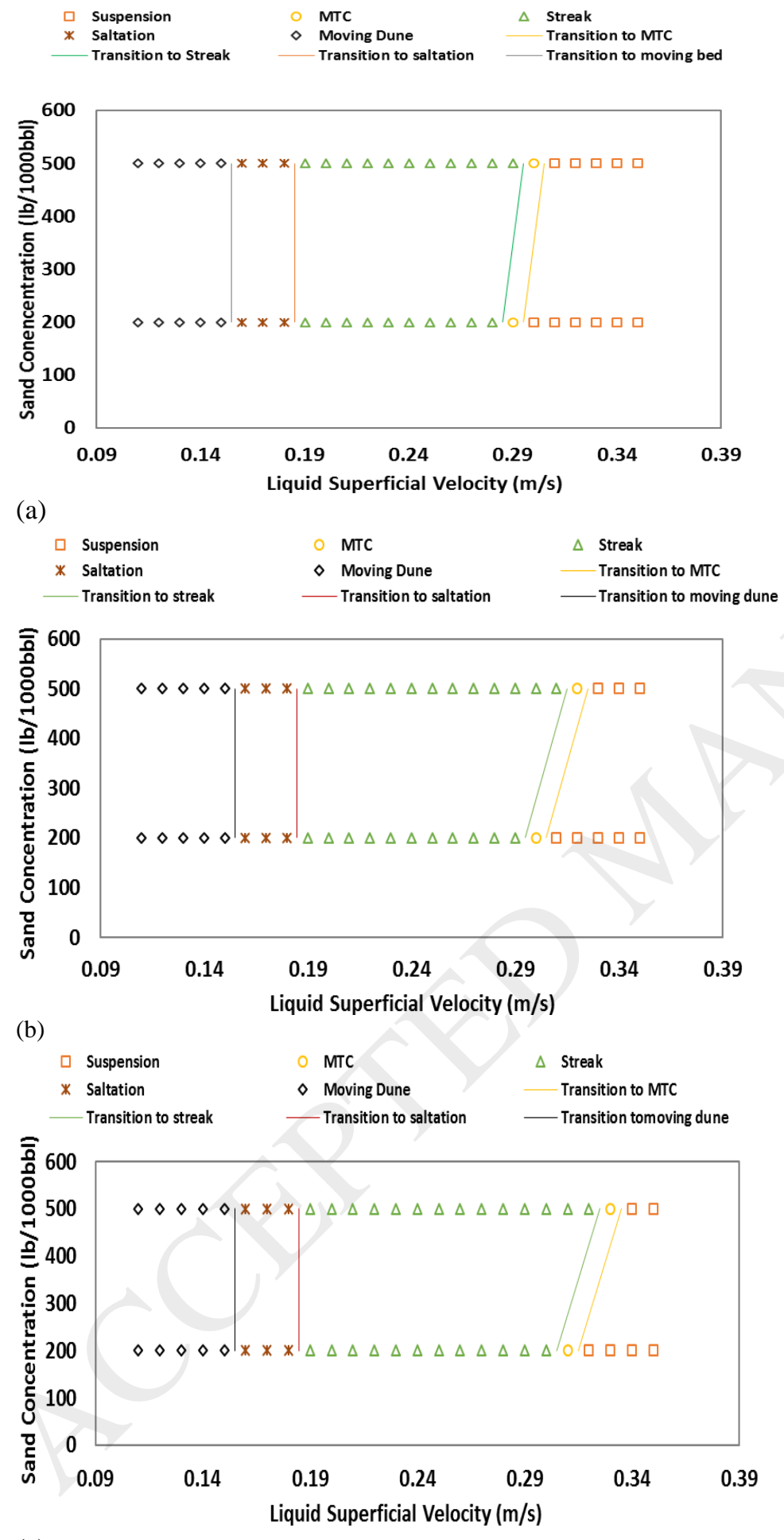

(c)

Figure 2: Sand-water flow patterns for sand particle sizes of (a) $212 \mu \mathrm{m}$, (b) 500 and (c) $800 \mu \mathrm{m}$ 


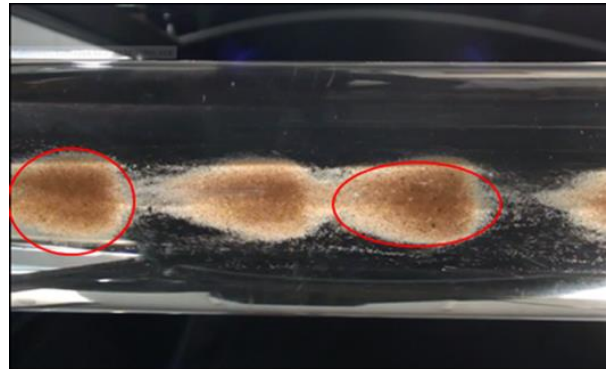

(a)

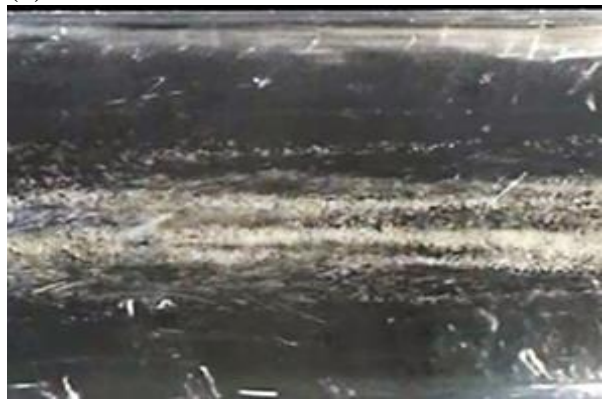

(b)

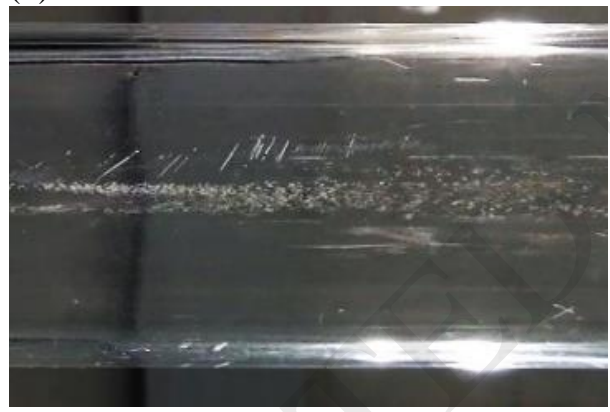

(c)

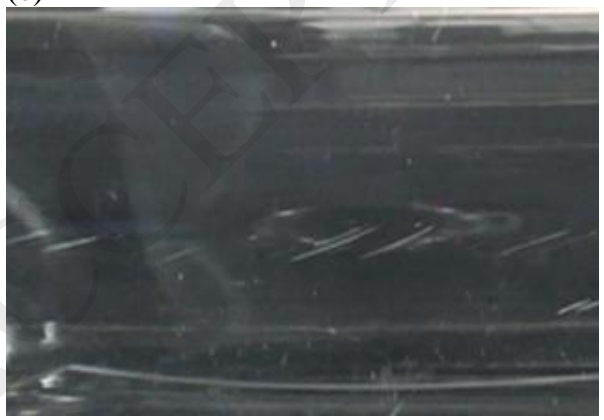

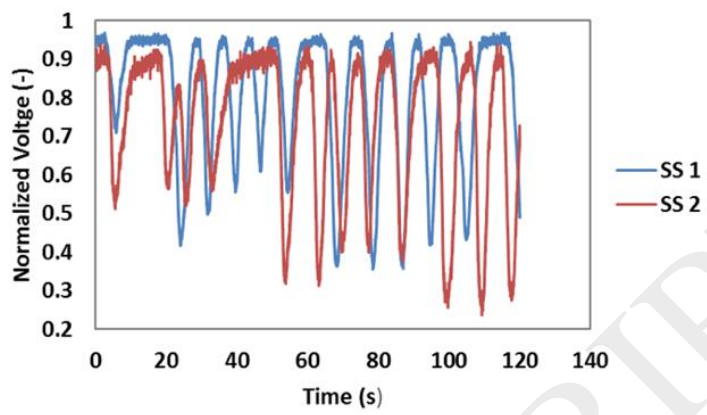
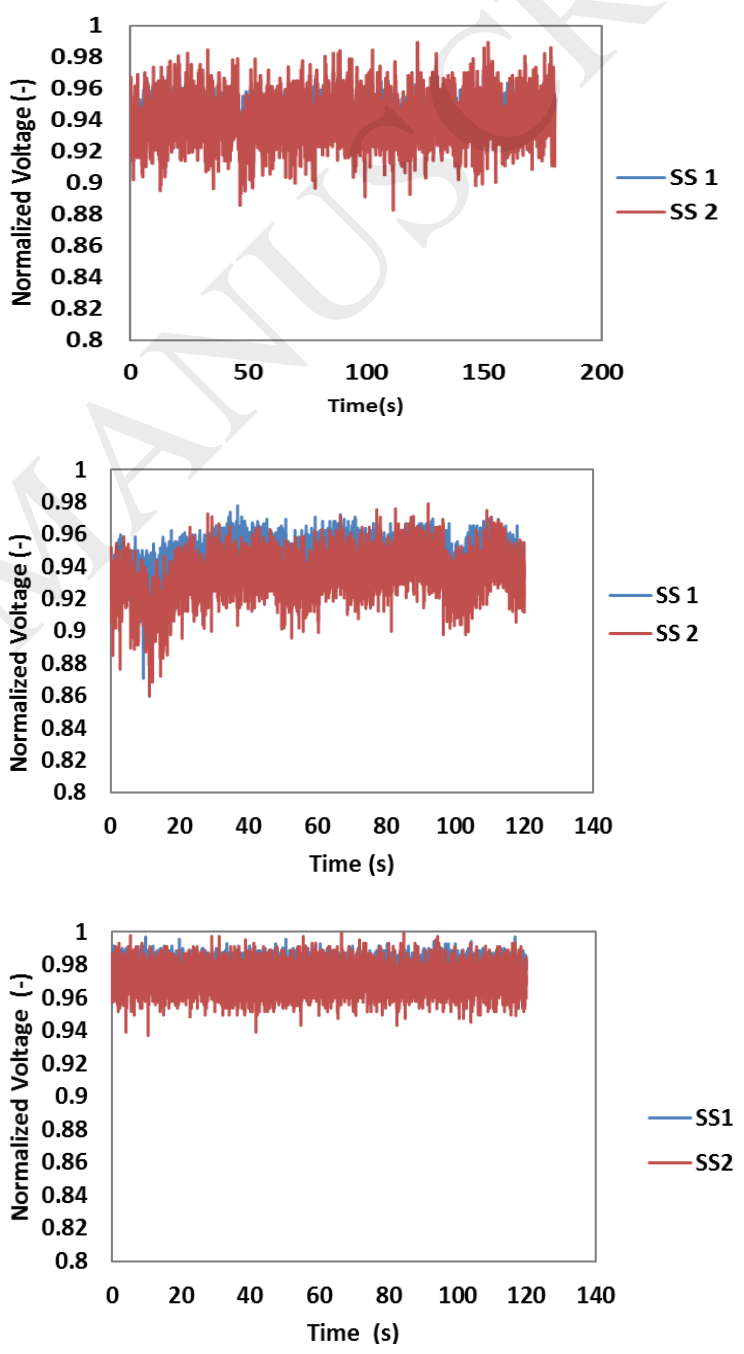

(d)

Figure 3: Typical sand-air-water flow regimes (left) with signals from SS1 and SS2 (right) referring to Sand Sensors 1 and 2 respectively (a) Moving sand dunes regime at $V_{s l}=0.10 \mathrm{~m} / \mathrm{s}, V_{s g}=4.0 \mathrm{~m} / \mathrm{s}, C_{v}=500 \mathrm{bl} / 1000 \mathrm{bbl}$ (b) Sand Streak below MTC $V_{s l}=0.28 \mathrm{~m} / \mathrm{s}, V_{s g}=4.2 \mathrm{~m} / \mathrm{s}, C_{v}=500 \mathrm{bbl} / 1000 \mathrm{bbl}$ ) (c) Sand Streak at MTC at $V_{s l}=0.31 \mathrm{~m} / \mathrm{s}, V_{s g}=3.9 \mathrm{~m} / \mathrm{s}, C_{v}=500 \mathrm{bl} / 1000 \mathrm{bbl}(\mathrm{d})$ Sand suspension regime at $V_{s l}=0.34 \mathrm{~m} / \mathrm{s}, V_{s g}=4.4 \mathrm{~m} / \mathrm{s}$, $C_{v}=500 \mathrm{bl} / 1000 \mathrm{bbl}$. Results are at $212 \mu \mathrm{m}$. 


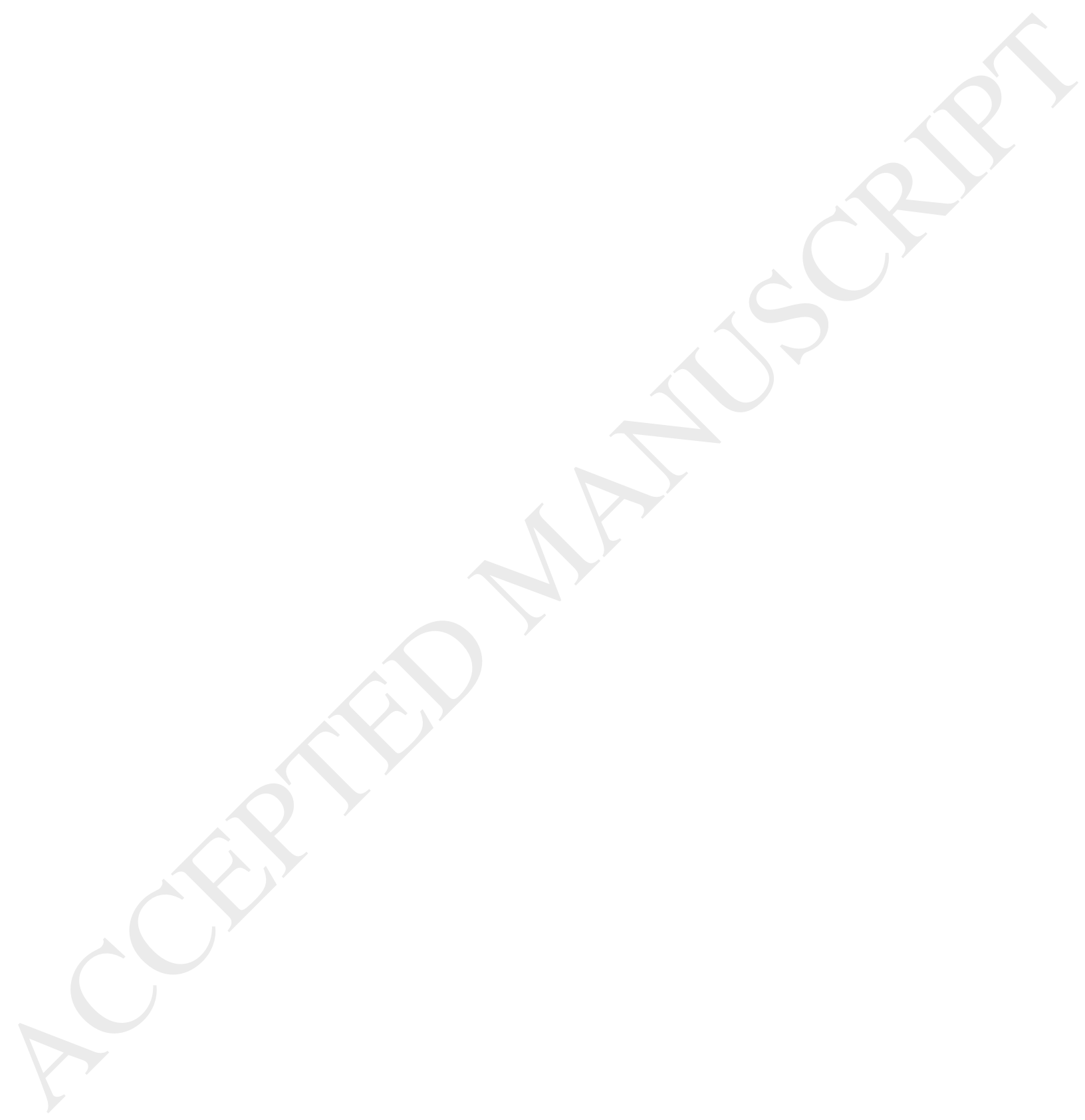



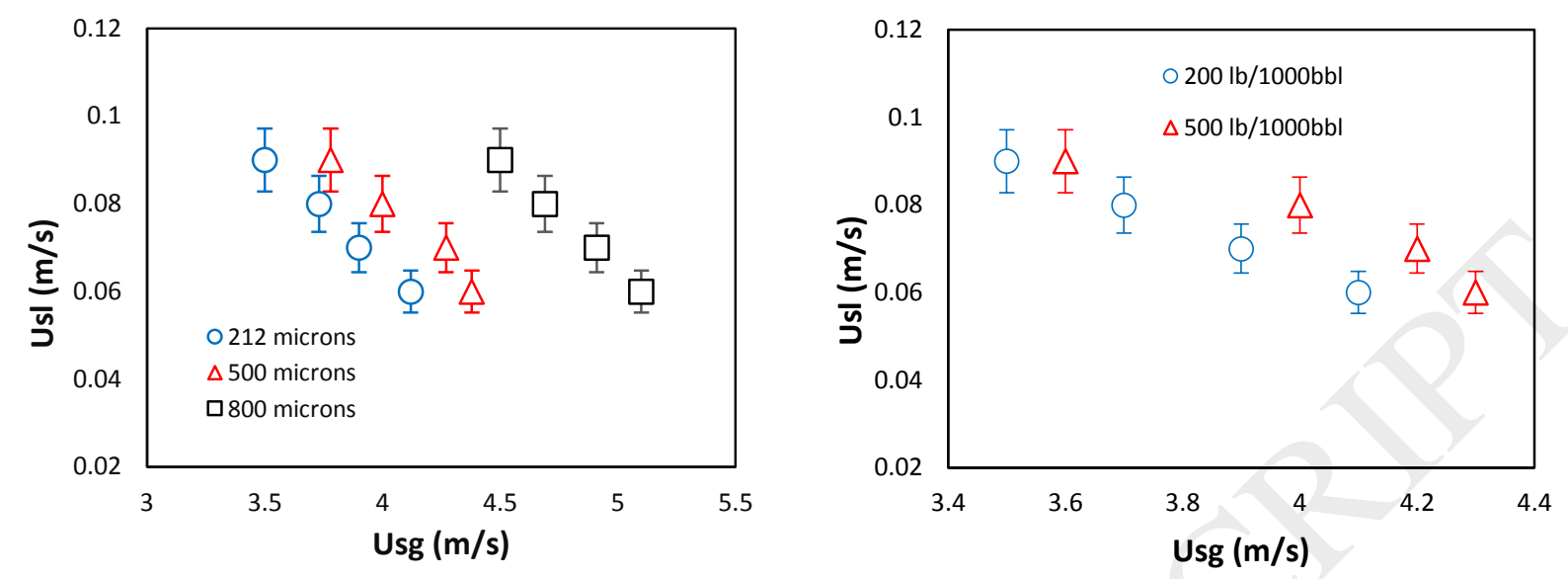

Figure 4: (a) Particle size effect on minimum transport conditions at concentration of $200 \mathrm{Ib} / 1000 \mathrm{bbl}(212,500$ and $800 \mu \mathrm{m}$ particle size) (b) Minimum transport condition for particle concentration in stratified flow (airwater flow) particle size of $212 \mu m$ 


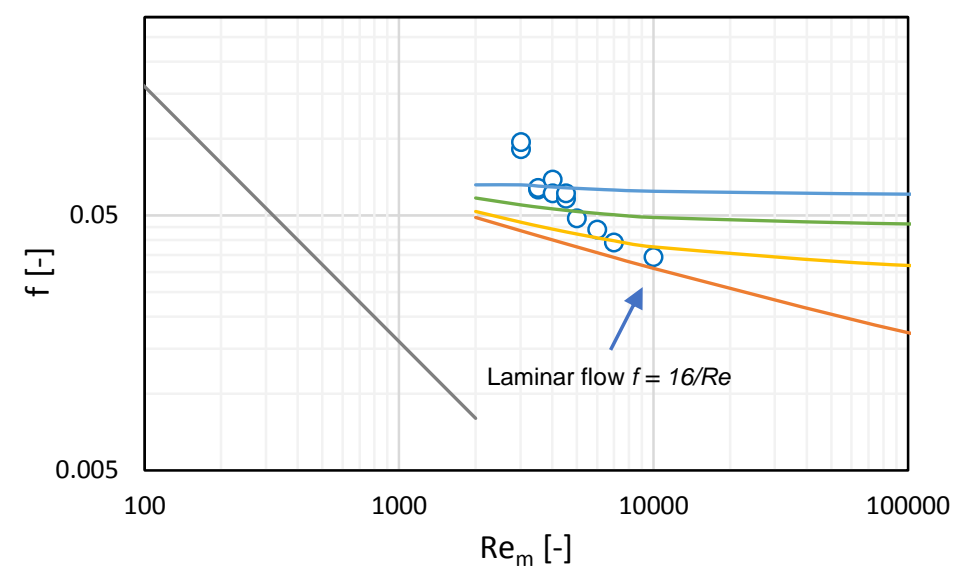

$\varepsilon / D=0.050$
$\varepsilon / D=0.020$
$\varepsilon / D=0.005$
$\varepsilon / D=0.000$

Figure 5: Comparison of current pipe friction factor with sand particles (markers) against the Moody diagram for pipes with water only with different pipe roughnesses, where $\varepsilon / D=0.000$ is for single-phase water in a smooth pipe 


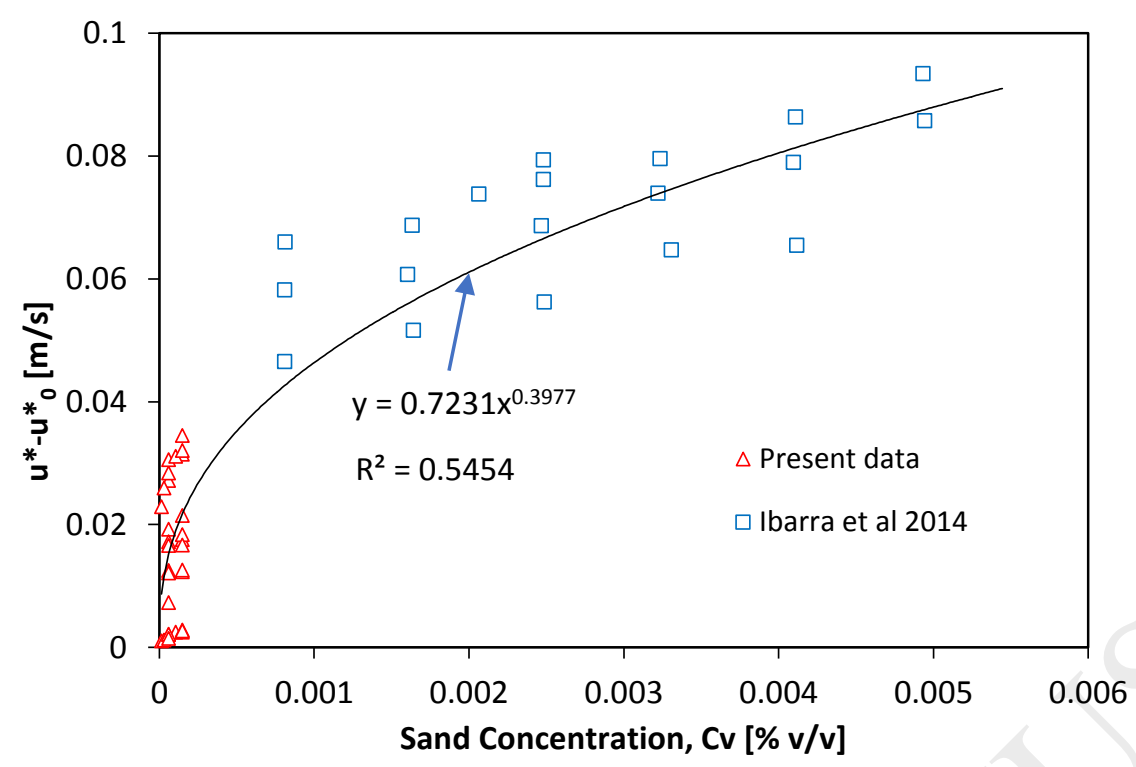

Figure 6: Sand MTC correlation: comparing data and modified Thomas-type correlations. All markers represent measured data while lines are correlations. 
Table 1: Summary of previous studies on sand transport and proposed models in single and multiphase flow systems

\begin{tabular}{|c|c|c|c|c|c|}
\hline Investigator(s) & $d_{p}(\mu \mathrm{m})$ & $\begin{array}{l}\text { Fluids/ } \\
d_{\text {pipe }}(\mathbf{m})\end{array}$ & $\begin{array}{l}\text { Particles/ } \\
\mathrm{C}_{\mathrm{V}}(\mathrm{v} / \mathrm{v})\end{array}$ & Correlation/model & Comments \\
\hline $\begin{array}{l}\text { (Oudeman, } \\
1992)\end{array}$ & $\begin{array}{l}150, \quad 300 \\
\text { and } 690\end{array}$ & $\begin{array}{l}\text { Water \& } \\
\text { viscosified } \\
\text { water } / 0.07\end{array}$ & Sand/n/a & $\begin{array}{r}\varphi_{\mathrm{sa}}=\frac{\mathrm{S}}{\sqrt{\mathrm{d}^{3} \mathrm{~g}\left(\frac{\text { Solid densiy }}{\text { Liquid density }}-1\right)}} \\
\varphi_{\mathrm{Li}}=\frac{\mathrm{U}_{\mathrm{b}}^{2}}{\operatorname{gd}\left(\frac{\text { Solid density }}{\text { Liquid density }}-1\right)}\end{array}$ & $\begin{array}{l}\text { Where } \\
\text { quantities } \varphi_{\text {sa }} \text { and } \\
\varphi_{\mathrm{Li}} \text { sand and fluid } \\
\text { transport parameters. } \\
\text { Effect por } \\
\text { concentration was not } \\
\text { considered. }\end{array}$ \\
\hline $\begin{array}{l}\text { (King et al., } \\
2001)\end{array}$ & $1,3,150,300$ & $\begin{array}{l}\text { Water \& } \\
\text { CMC/0.0152 }\end{array}$ & $\begin{array}{l}\text { Sand/ } \\
0.00005\end{array}$ & $\left.\frac{\Delta \mathrm{P}}{\Delta \mathrm{L}}\right|_{M T C}=\frac{4 \rho_{\mathrm{L}\left(\mathrm{U}_{\mathrm{mtc}}\right)^{2}}}{\mathrm{~g}_{\mathrm{c}} \mathrm{D}}$ & $\begin{array}{l}\text { effect of oil or water } \\
\text { prewetting of the } \\
\text { solids on solids } \\
\text { transport } \\
\text { investigated. Pressure } \\
\text { gradient required for } \\
\text { MTC to occur was } \\
\text { modelled }\end{array}$ \\
\hline $\begin{array}{l}\text { (Danielson and } \\
\text { Co, 2007) }\end{array}$ & 280,550 & $\begin{array}{l}\text { Exxsol D80 } \\
\& \\
\text { water)/0.069 }\end{array}$ & $\begin{array}{l}\text { Sand } / 0.0005 \\
0.0002,0.0005\end{array}$ & $\mathrm{u}_{\mathrm{mtc}}=\mathrm{Kv}^{-\frac{1}{9}} \mathrm{~d}_{\mathrm{p}}^{\frac{1}{9}}(\mathrm{gD}(\mathrm{s}-1))^{5 / 9}$ & $\begin{array}{lr}\text { Empirical } & \text { model } \\
\text { developed } & \text { from } \\
\text { simulations using } & \text { using } \\
\text { OLGA. Validation } \\
\text { using experimental } \\
\text { data required. }\end{array}$ \\
\hline (Yan, 2010) & 200,750 & Water/0.054 & Sand/0.001 & $\begin{array}{l}\mathrm{u}_{\mathrm{c}}^{*}=\mathrm{u}_{0}^{*}+0.7176 \mathrm{C}_{\mathrm{v}}^{0.5099} \text { for } \mathrm{C}_{\mathrm{v}}<0.0005 \mathrm{v} / \mathrm{v} \\
\mathrm{u}_{\mathrm{c}}^{*}=\mathrm{u}_{0}^{*}+0.0776 \mathrm{C}_{\mathrm{v}}^{0.2032} \text { for } \mathrm{C}_{\mathrm{v}} \geq 0.0005 \mathrm{v} / \mathrm{v}\end{array}$ & $\begin{array}{lr}\text { Modified Thomas' } \\
\text { lower model, but very } \\
\text { low } \\
\text { concentration } \\
\text { used. }\end{array}$ \\
\hline $\begin{array}{l}\text { (Stevenson and } \\
\text { Thorpe, 2002) }\end{array}$ & 512,1010 & $\begin{array}{l}\text { Water and } \\
\text { Rheovis/0.07, } \\
0.59\end{array}$ & $\begin{array}{l}\text { Sand } \\
\& \\
\text { Lead, } 0.001\end{array}$ & $\begin{array}{c}\frac{\mathrm{u}_{\mathrm{p}}}{\mathrm{u}_{\mathrm{l}}}=0.95\left[1+\frac{\mathrm{U}_{\mathrm{sg}}}{\mathrm{U}_{\mathrm{sl}}}\right]-\left[1.38 \frac{\mathrm{U}_{\mathrm{sg}}}{\mathrm{U}_{\mathrm{sl}}}+0.88 \sqrt{\mathrm{Fr}_{\mathrm{l}}}\right] \\
*\left[\mathrm{~N}_{\operatorname{Re}(\mathrm{l})} \sqrt{\left.\mathrm{Fr}_{\mathrm{l}}\left(\frac{d}{\mathrm{D}}\right)^{1.5}\right]^{-0.180}}\right. \\
w_{C}=3.43 d^{-0.034} v^{0.34}\left[\mathrm{~g}(s-1) D_{f}\right]^{0.33}\end{array}$ & $\begin{array}{l}\text { Correlation } \\
\text { developed based on } \\
\text { particle to liquid } \\
\text { velocity ratios } U_{\mathrm{P}} / \mathrm{U}_{\mathrm{l}} \\
\text { with respect to liquid } \\
\text { Froude and Reynolds } \\
\text { numbers }\end{array}$ \\
\hline (Davies, 1987) & - & - & - & $\begin{array}{l}\text { Obtained from turbulent theory and other's data } \mathrm{u}_{c}= \\
1.08\left(1+3.64 \mathrm{C}_{\mathrm{v}}\right)^{1.09}(1- \\
\left.\mathrm{C}_{\mathrm{v}}\right)^{0.55 n_{v}-0.09} \mathrm{~d}_{\mathrm{p}}^{0.18}\left[\frac{[\mathrm{gg} \Delta \rho}{\rho_{L}}\right]^{0.54} \mathrm{D}^{0.46}\end{array}$ & $\begin{array}{l}\text { Theoretical model } \\
\text { based on turbulence } \\
\text { theory. Effect of fluid } \\
\text { properties e.g. } \\
\text { viscosity not } \\
\text { accounted for. }\end{array}$ \\
\hline
\end{tabular}




\begin{tabular}{|c|c|c|c|c|c|}
\hline $\begin{array}{l}\text { (Oroskar and } \\
\text { Turian, 1980) }\end{array}$ & - & - & - & $\begin{array}{l}\frac{\mathrm{u}_{\mathrm{c}}}{\sqrt{\mathrm{gd}_{\mathrm{p}}(\mathrm{s}-1)}} \\
=1.85 \mathrm{C}_{v}{ }^{0.1536}((1 \\
\left.\left.-\mathrm{C}_{v}\right)^{0.3564}\left(\frac{\mathrm{D}}{\mathrm{d}_{\mathrm{p}}}\right)^{-0.378} \frac{\mathrm{D} \rho_{\mathrm{l}} \sqrt{\operatorname{gd}_{p}(\mathrm{~s}-1)}}{\mu_{\mathrm{L}}}\right) \mathrm{ED}^{0.30}\end{array}$ & $\begin{array}{l}\text { Obtained from } \\
\text { turbulent theory and } \\
\text { other's data } \\
\mathrm{v} / \mathrm{v} \text { of } 0.1 \sim 0.50, \mathrm{~s}= \\
\rho_{\mathrm{p}} / \rho_{\mathrm{L}}\end{array}$ \\
\hline $\begin{array}{l}\text { (Ibarra et al., } \\
\text { 2014) }\end{array}$ & 211-297 & Water/0.0962 & $\begin{array}{l}\text { Sand/0.0008- } \\
0.0048\end{array}$ & $\begin{aligned} \frac{\mathrm{u}_{\mathrm{c}}}{\sqrt{\mathrm{gd}_{\mathrm{p}}(\mathrm{s}-1)}}=1.3277\left(\frac{\mathrm{u}_{\mathrm{sl}}}{\mathrm{u}_{\mathrm{c}}}\right)^{0.33}(1 \\
\left.\quad-\mathrm{C}_{v}\right)^{-35.49}\left(\frac{\mathrm{D}}{\mathrm{d}_{\mathrm{p}}}\right)^{-0.378} \mathrm{Re}_{l, c}{ }^{0.09}\end{aligned}$ & $\begin{array}{l}\text { Modified Oroskar \& } \\
\text { Turian's model by } \\
\text { introducing a liquid } \\
\text { critical Reynolds } \\
\text { number }\end{array}$ \\
\hline $\begin{array}{l}\text { (Leporini et al., } \\
\text { 2018) }\end{array}$ & & Water/0.063 & $\begin{array}{l}\text { Sand } / 0.000065- \\
0.00056\end{array}$ & $\mathrm{n} / \mathrm{a}$ & $\begin{array}{l}\text { A comprehensive } \\
\text { study was done with } \\
\text { low sand } \\
\text { concentrations but no } \\
\text { model r was } \\
\text { developed. }\end{array}$ \\
\hline
\end{tabular}


Table 2: List of instruments

\begin{tabular}{|c|c|c|c|c|}
\hline Abbreviation & Equipment & Description & Full range & Uncertainty \\
\hline $\mathrm{P} 1$ & Pressure Transducer 1 & $\begin{array}{l}\text { Druck PMP } 4070 \\
\text { (Pressure Measurement) }\end{array}$ & $0 \sim 6$ bar & $\pm 0.06 \%$ \\
\hline $\mathrm{P} 2$ & Pressure Transducer 1 & $\begin{array}{l}\text { Druck PMP } 4070 \\
\text { (Pressure Measurement) }\end{array}$ & $0 \sim 6$ bar & $\pm 0.06 \%$ \\
\hline CR1 and CR2 & $\begin{array}{l}\text { Conductivity Ring } 1 \\
\text { and } 2\end{array}$ & $\begin{array}{l}\text { Manufactured in Oil and } \\
\text { Gas Engineering Centre } \\
\text { Lab } \\
\text { (Liquid Hold-up) }\end{array}$ & $0 \sim 1$ & $( \pm 2.4 \%)^{*}$ \\
\hline SS1 and SS2 & Sand Sensors 1 and 2 & $\begin{array}{l}\text { Manufactured in Oil and } \\
\text { Gas Engineering Centre } \\
\text { Lab } \\
\text { (Sand detection and } \\
\text { monitoring) }\end{array}$ & $0 \sim 3.8 \mathrm{~mm}$ & $( \pm 3.6 \%) *$ \\
\hline Air Flowmeter & $\begin{array}{l}\text { Proline t-mass } 651 \\
\text { Thermal Flowmeter }\end{array}$ & $\begin{array}{l}\text { Proline t-mass 65F Thermal } \\
\text { Flowmeter } \\
\text { Endress + Hauser } \\
\text { (Gas Superficial Velocity) }\end{array}$ & $0 \sim 70 \mathrm{~m}^{3} \mathrm{~h}^{-1}$ & $\pm 0.15 \%$ \\
\hline MFW1 & $\begin{array}{l}\text { Magnetic Flowmeter } \\
\text { (Liquid) }\end{array}$ & $\begin{array}{l}\text { ABB K280/0 AS } \\
\text { (Liquid } \quad \text { Superficial } \\
\text { Velocity) }\end{array}$ & $0 \sim 20 \mathrm{~m}^{3} \mathrm{~h}^{-1}$ & $\pm 0.8 \%$ \\
\hline FW2 & $\begin{array}{l}\text { Magnetic Flowmeter } \\
\text { (Sand + Water) }\end{array}$ & $\begin{array}{l}\text { OPTIFLUX 2300C Krohne } \\
\text { Magnetic Flowmeter }\end{array}$ & $0 \sim 21 \mathrm{~m}^{3} \mathrm{~h}^{-1}$ & $0.2 \%$ \\
\hline
\end{tabular}

* Determined through three repeated calibration tests. 
Table 2: Experimental test matrix and sand properties

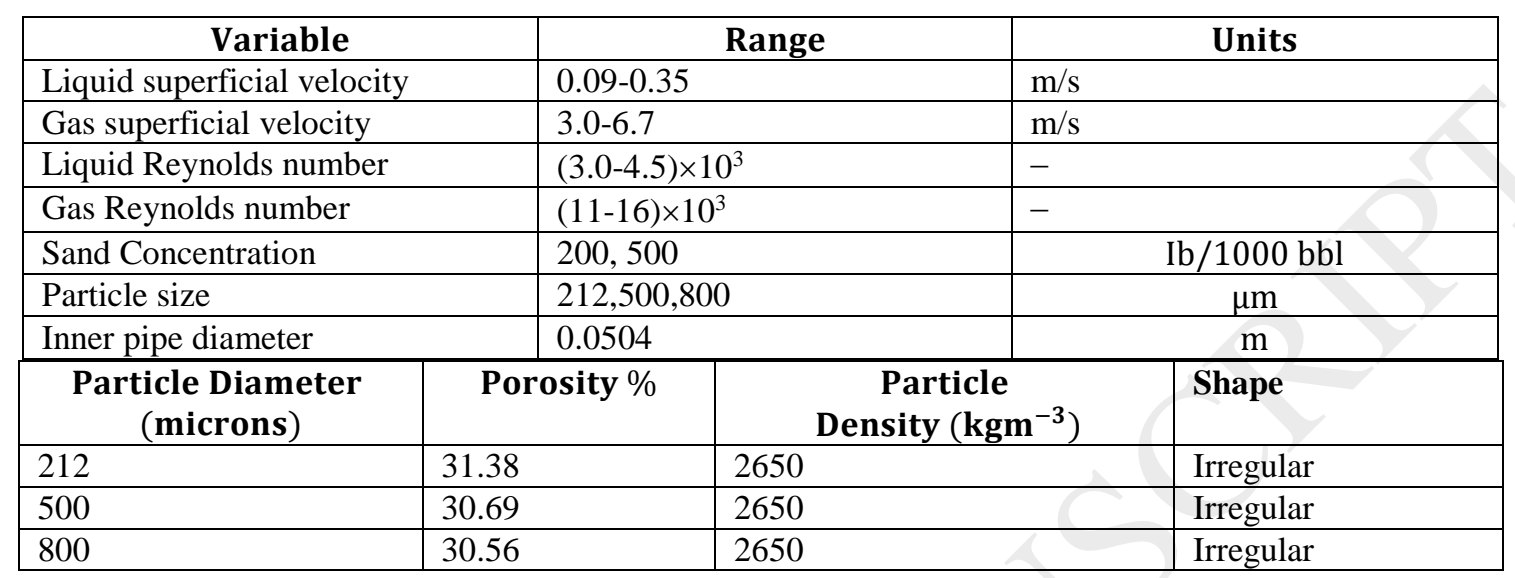


Table 4: Comparison of predicted MTCs from proposed correlation with experimental MTCs

\begin{tabular}{|c|c|c|c|c|c|c|c|}
\hline $\begin{array}{l}d_{p} \\
(\mu \mathbf{m})\end{array}$ & $\begin{array}{c}C_{v} \\
(\mathbf{l b} / \mathbf{1 0 0 0 b b l})\end{array}$ & $\begin{array}{c}V_{s l} \\
(\mathbf{m} / \mathbf{s})\end{array}$ & $\begin{array}{l}V_{s g} \\
(\mathrm{~m} / \mathrm{s})\end{array}$ & $\begin{array}{c}\boldsymbol{H}_{l} \\
(-)\end{array}$ & $\begin{array}{l}V_{L, M T C} \\
(\exp ) \\
(\mathrm{m} / s)\end{array}$ & $\begin{array}{l}V_{L, M T C} \\
(\text { pred }) \\
(\mathrm{m} / \mathrm{s})\end{array}$ & $\begin{array}{l}\text { PAE } \\
(\%)\end{array}$ \\
\hline 212 & 200 & 0.06 & 4.12 & 0.26 & 0.23 & 0.25 & 8.70 \\
\hline 212 & 500 & 0.06 & 4.29 & 0.25 & 0.24 & 0.28 & 16.67 \\
\hline 212 & 200 & 0.07 & 3.90 & 0.27 & 0.26 & 0.3 & 15.38 \\
\hline 212 & 500 & 0.07 & 4.19 & 0.21 & 0.33 & 0.34 & 3.03 \\
\hline 212 & 200 & 0.08 & 3.73 & 0.24 & 0.34 & 0.34 & 3.03 \\
\hline 212 & 500 & 0.08 & 4.00 & 0.22 & 0.36 & 0.35 & 2.78 \\
\hline 212 & 200 & 0.09 & 3.55 & 0.24 & 0.38 & 0.39 & 2.63 \\
\hline 212 & 500 & 0.09 & 3.62 & 0.23 & 0.39 & 0.35 & 10.26 \\
\hline 500 & 200 & 0.06 & 4.33 & 0.25 & 0.24 & 0.26 & 8.33 \\
\hline 500 & 500 & 0.06 & 4.70 & 0.24 & 0.25 & 0.28 & 12.00 \\
\hline 500 & 200 & 0.07 & 4.20 & 0.21 & 0.33 & 0.3 & 9.09 \\
\hline 500 & 500 & 0.07 & 4.30 & 0.20 & 0.35 & 0.33 & 5.71 \\
\hline 500 & 200 & 0.08 & 4.00 & 0.23 & 0.35 & 0.37 & 5.71 \\
\hline 500 & 500 & 0.08 & 4.20 & 0.22 & 0.36 & 0.38 & 5.56 \\
\hline 500 & 200 & 0.09 & 3.78 & 0.23 & 0.39 & 0.4 & 2.56 \\
\hline 500 & 500 & 0.09 & 4.00 & 0.20 & 0.45 & 0.41 & 8.89 \\
\hline 800 & 200 & 0.06 & 5.10 & 0.24 & 0.25 & 0.25 & 0.00 \\
\hline 800 & 500 & 0.06 & 5.40 & 0.22 & 0.27 & 0.29 & 7.41 \\
\hline 800 & 200 & 0.07 & 4.91 & 0.20 & 0.35 & 0.4 & 14.29 \\
\hline 800 & 500 & 0.07 & 5.10 & 0.19 & 0.37 & 0.46 & 24.32 \\
\hline 800 & 200 & 0.08 & 4.69 & 0.22 & 0.36 & 0.37 & 2.78 \\
\hline 800 & 500 & 0.08 & 4.85 & 0.21 & 0.38 & 0.38 & 0.00 \\
\hline 800 & 200 & 0.09 & 4.50 & 0.21 & 0.42 & 0.43 & 0.00 \\
\hline 800 & 500 & 0.09 & 4.69 & 0.20 & 0.45 & 0.46 & 2.22 \\
\hline
\end{tabular}

